City University of New York (CUNY) CUNY Academic Works

2015

\title{
ALA Annual 2015 LITA/ALCTS Joint Electronic Resource Management Interest Group Report
}

Junior R. Tidal

CUNY New York City College of Technology

\section{How does access to this work benefit you? Let us know!}

More information about this work at: https://academicworks.cuny.edu/ny_pubs/44

Discover additional works at: https://academicworks.cuny.edu

This work is made publicly available by the City University of New York (CUNY).

Contact: AcademicWorks@cuny.edu 
This is a preprint of an article submitted for consideration in the Journal of Electronic Resource Librarianship 2015 Junior Tidal

Journal of Electronic Resource Librarianship is available online at: http://www.tandfonline.com/loi/wacq20\#.Vw_eeNQrLfU

\title{
ALA ANNUAL 2015 LITA/ALCTS JOINT ELECTRONIC RESOURCE
}

MANAGEMENT INTEREST GROUP REPORT

\author{
Reporter: Junior Tidal, New York City College of Technology, CUNY
}

Presenters: Wendolyn Vermeer, Cal Poly Pomona University and Rose Reynolds, Smith

\section{College Libraries}

This past June, I attended the American Libraries Association Annual Conference in San Francisco, California. While there, I observed two presentations at the Library Information Technology Association (LITA) Interest/Association for Library Collections \& Technical Services (ALCTS) Electronic Resource Management (ERM) joint interest group meeting, organized by the ALCTS Acquisitions Section’s Acquisitions Technology Committee. Wendolyn Vermeer of Cal Poly Pomona University Library and Rose Reynolds of Smith College Libraries gave overviews of the ERM system they had used.

Robert Heaton, co-chair of the LITA/ALCTS ERM IG, began the meeting with a brief overview of ERMs. Beginning in the mid 90s, ERMs were developed in-house to keep track of records including information such as eResource names, URLs, vendors, licenses, and the like. Ten years ago, vendors and open source software developers took a hand at creating ERMs, many of which are used today.

Heaton mentioned future trends included a more centralized ERM system, either as a 
supplemental cloud component or unified with a library's existing integrated library system. This integrated ERM would include support for print and eResources, consistent information, and flexible enough for additional information such as fields and metadata. Further, Heaton identified specific vendors and open-source developers working on ERMs.

Vermeer's presentation, entitled “All the Things? An ERMS Cautionary Tale," described the use of Cal Poly University Library's ERM system. She discussed how an ideal ERM should be able to support the workflow of electronic resources, including processing, license management, statistics, and local notes in a centralized manner.

Vermeer described how processing eResources was manageable early on in the late 90s. However, in 2004

the proliferation of eBooks, electronic journals, and databases had increased significantly, making them more difficult to maintain. Additionally, the Cal Poly University Library had experienced two server migrations, a retiree who left with a binder full of eResource password information, updates to their domains and authentication methods, and the addition of a new discovery layer. This caused problems in fully integrating these databases.

Many problems were solved using Innovative Interface’s Sierra ERM. This system provided symbolic links and a more usable interface. Vermeer mentioned creating partnerships with the ERM vendor and user community. She also stressed the importance of identifying user needs, done through using Google Analytics data and Google Tag Manager. She echoed Heaton's remarks on the importance of an ERM's flexibility. ERMs should be able to change with new resources and formats, as well as be scalable and sustainable. 
Following Vermeer's presentation, Rose Reynolds discussed, “Meeting The E-resources Challenge: Utilizing ERMS in Libraries,” which focused on Smith College library’s use of CORAL. Reynolds discussed the background of Smith College's library, which uses SFX (open link resolver), EBSCO Discovery Service, and Aleph. She described before Prior to the implementation

of their ERM, a complicated workflow was used to add a single electronic resource. This involved several different librarians and support staff exchanging hardcopy printouts and folders of an electronic resource, including information such as licensing and the resource's characteristics (names, URLs, and vendors,ete.).

In order to better streamline the workflow, the library investigated the use of an ERM. Identifying problems of the current setup, the ERM was meant to reach a number of goals, including the reduction of paper, the need for institutional memory, and to create a better understanding of

eResource packages. Also it would create a centralized point for troubleshooting, and reduce the number of emails

between staff.

One solution was the creation of a Google site, consistent with Smith College's adoption of Google Apps. An email login was shared for staff access. Following the implementation of an eResource, the librarians were able to identify what information to keep record of. This system integrated with Google calendar to highlighte renewal dates. An online forum was used to keep track of communication regarding each eResource, documenting implementation and problems. 
Although the Google site was useful, it did have a number of drawbacks. This system was rigid as it had no standardized fields or structured data. It also did not streamline the workflow process, and was problematic for non-packaged resources.

Reynolds next described the adoption of CORAL, which stands for Centralized Online Resources

Acquisitions and Licensing, an open-source ERM. CORAL was developed by the University of Notre

Dame's Hesburgh Libraries, and is a web-based modular system that tracks an eResource through its lifecycle: acquisition, licensing, administration, support, and usage. Reynolds explained that CORAL had a built-in communication system, a status tracker for each eResource (purchase, subscription or trial), a status system for steps of the workflow, and a system that tracked important dates (renewal and creation). It also kept records of vendor information, licenses, and statistics management.

Since CORAL is open-source, the system is highly customizable. Staff at Smith created a mobile-friendly version of CORAL for instance. A developer community also exists, rolling out new ideas and innovations, such as implementing the open-source YOURLS, which stands for Your Own URL Shortener, a url shortening

system which can create stable shorter links. There are also implementations of CORAL which can be integrated with Bootstrap, a popular web framework created by two Twitter developers, that optimizes sites for mobile devices.

Attending this crowded meeting, I felt very engaged by these presentations. I was impressed by 
Vermeer's remarks on the user experience with ERMs. As the Web Services and Multimedia Librarian at my institution, I don't directly oversee the implementation of our eResources, yet I understand the importance of considering usability for any type of system. Documenting workflows becomes a moot point if users cannot complete their tasks within the ERM. After all, keeping track of URLs, vendor information, packages, dates, and workflows can be quite laborious, and is necessary for a system to adequately support this in a usable manner. I also agree that eResources are constantly changing, and ERM flexibility is important. As more librarians utilize tablet computers and mobile devices, the necessity of the mobile optimizations Reynolds discussed in her overview of CORAL becomes more apparent. Even more so, ERMs

should be adaptable to support new types of data, unknown future formats, and workflows. Presenter information and slides can be found on the ALA Annual 2015 online program site http://alaac15.ala.org/node/28706.

Junior Tidal is Assistant Professor/Web Services \& Multimedia Librarian at the New York City College of Technology, CUNY. He can be contacted by phone at (718) 260-5481, and email at JTidal@citytech.cuny.edu. 